\title{
Justicia transicional, el diálogo y la reflexividad crítica: tejiendo pensamientos*
}

\author{
Lieselotte Viaene \\ Universidad Carlos III de Madrid \\ ORCID ID 0000-0001-8507-4006 \\ lviaene@clio.uc3m.es
}

\section{Cita recomendada:}

Viaene, L. (2020). Justicia transicional, el diálogo y la reflexividad crítica: tejiendo pensamientos. Eunomía. Revista en Cultura de la Legalidad, 18, pp. 416-423.

doi: https://doi.org/10.20318/eunomia.2020.5287

Recibido / received: 06/03/2020

\begin{abstract}
«De vez en cuando camino al revés: es mi modo de recordar. Si caminara sólo hacia adelante, te podría contar cómo es el olvido.» Humberto Ak'abal ${ }^{1}$
\end{abstract}

Comienzo con un agradecimiento profundo a José María Sauca y al equipo editorial de Eunomía por haber seleccionado mi libro Nimla rahilal. Pueblos indígenas y justicia transicional: reflexiones antropológicas, publicado el año pasado, aunque ya concebido hace muchos años atrás, como objeto de esta sección Book Forum.

Las reflexiones de mis apreciados interlocutores Javier Dorado Porras, colega profesor e investigador de la Universidad Carlos III de Madrid, y Pedro Garzón López, investigador postdoctoral e indígena chinanteo (México), me recordaron la importancia de "caminar al revés». Como describe mi poeta favorito, el finado Humberto Ak'akal, maya quiché de Guatemala, de vez en cuando hay que «caminar al revés» y meditar sobre de dónde vengo, dónde estoy y hacía dónde me gustaría ir y por qué.

Desde hace casi un año estoy recorriendo un nuevo sendero académico como investigadora principal del proyecto de investigación RIVERS-¿Agua/derechos humanos más allá de lo humano? Ontologías indígenas del agua, encuentros plurilegales y traducción interlegal (2018-2024), gracias a una Starting Grant recibida en 2018 por el Consejo Europeo de Investigación (ERC, por sus siglas en ingles)².

\footnotetext{
* Esta publicación ha sido posible gracias al financiamiento por el Consejo Europeo de Investigación (ERC) bajo el programa de investigación y innovación H2020 de la Unión Europea (Acuerdo de subvención No 804003).

${ }^{1}$ H. Ak'abal, 2001, 'Camino al revés', Ajkem Tzij. Tejedor de palabras, Cholsamaj, Guatemala, p.20.

2 Más información: www.rivers-ercproject.eu.
} 
Esta nueva travesía intelectual tiene como pregunta principal: ¿hasta qué punto el derecho internacional de los derechos humanos puede abarcar y entender las realidades plurilegales del agua? RIVERS aborda una de las cuestiones más apremiantes de este siglo: la relación entre los seres humanos y la "Naturaleza". Con un equipo de investigación interdisciplinario e internacional, esperamos poder esclarecer críticamente posibles caminos hacia un cambio urgente de paradigma del marco de los derechos humanos que vaya más allá de los supuestos modernos dominantes sobre cultura/Naturaleza y lo humano/no-humano. Colombia, Guatemala, Nepal y el sistema de protección de los derechos humanos de las Naciones Unidas son los contextos donde se desarrollará una investigación empírica e antropológica jurídica.

Honestamente, caminar este nuevo sendero no hubiera sido posible sin previamente haber tenido la oportunidad de conocer profundamente y caminar literalmente muchas sendas del territorio maya q'eqchi' de Guatemala en el contexto del «post» conflicto, que es el tema central del libro que está bajo discusión aquí. De hecho, en el acto de lanzamiento internacional de este proyecto de investigación que celebramos el pasado 8 de noviembre en la Universidad Carlos III de Madrid ${ }^{3}$, dediqué RIVERS a los fallecidos y sobrevivientes mayas del genocidio de Guatemala que han colaborado generosamente con mis investigaciones. Aprovechando este espacio quiero expresar esta dedicatoria formalmente porque la investigación que forma la base de este libro es, en realidad, fruto de un largo y profundo dialogo entre muchos lugares, muchas voces y muchos saberes que forman parte de este territorio q'eqchi'. Haber tenido el privilegio de caminar con muchos q'eqchi' estos senderos ha sido una experiencia muy transformadora porque, entre otras cosas, me enseñaron la existencia de una realidad más allá de la inmediata relativa a los conocimientos eurocéntricos enseñados en nuestras escuelas y universidades.

Como describí en este libro, para los mayas la palabra es sagrada y esto no es una simple metáfora, sino un hacer, una práctica, un modo de estar y vivir el mundo. En esta línea, nos explica mi colega antropólogo y apreciado amigo Carlos Fredy Ochoa (2014), que el Popol Vuj, la sagrada crónica antigua maya, nos enseña que el diálogo no es solamente un valor moral, sino también «un acto creador y fundador» y «la señal de nuestra existencia». Este pequeño texto pretende crear un diálogo escrito con los pensamientos de mis dos interlocutores, investigadores con formaciones y trayectorias académicas muy distintas. A su vez, mis colegas me invitan a seguir a delante con una actitud de "reflexividad crítica», que según los editores de la revista académica de referencia International Journal of Transitional Justice, es indispensable en el campo de justicia transicional porque solamente así «somos capaces de realizar algunas de nuestras múltiples subjetividades dentro de procesos co-constructivos de conocimiento dialógico y colectivo, evitando la tendencia a centrarnos 0 a desplazar a aquellos con cuyas historias buscamos dialogar, documentar y analizar» (Lykes y van der Merwe, 2019, p. 413). Efectivamente, como investigadora comprometida es necesario posicionarse, re-posicionarme realizando varios "giros" en el pensamiento académico que se ven reflejados en un tejido de pensamientos con muchos colores y diversas figuras. $Y$ como ocurre en el proceso

\footnotetext{
3 Acto Inaugural ERC proyecto RIVERS y seminario internacional, «The Rights of Nature: a legal revolution or ontological conflicts?», 8 de noviembre 2019 (UC3M), con participación de: Vicky TauliCorpus, UN Special Rapporteur on the Rights of Indigenous People, Anne Nuorgam, Chair of the United Nations Permanent Forum on Indigenous Issues (Sami, Finland), Belkis Izquierdo, Magistrada Arhuaca, Jurisdicción Especial para la Paz (JEP) (Colombia), Dambar Chemjong, Director Anthropology Department, Trivubhan University, (Limbu, Nepal), Guillermo Fernández-Maldonado, RepresentanteAdjunto, Oficina de las Naciones Unidas para los Derechos Humanos - Colombia. La grabación del seminario está disponible en: https://www.youtube.com/watch?v=VqqZyaP0NyQ
} 
de tejer, en ciertos momentos a veces hay que sacar un hilo que no quedó bien y poner otro.

\section{El dogma de la justicia como castigo penal: ¿una verdadera necesidad de los sobrevivientes de graves violaciones de derechos humanos?}

En la última sección de mi libro, «conclusiones y recomendaciones», invité a mis colegas académicos juristas, todos formados en la cultura jurídica dominante eurocéntrica y antropocéntrica, a no ignorar ni sentirse incómodos con saberes y prácticas indígenas, más bien a "tomar a los otros en serio», como nos invita el también antropólogo británico Tim Ingold en su libro recién publicado Anthropology: why it matters (2018). Para gran satisfacción mía, Javier Dorado Porras, colega y jurista, ha aceptado esta invitación con los brazos abiertos. A pesar de su «nula formación antropológica» y escasa experticia en cuestiones indígenas, ha realizado una reseña de este libro con un rigor académico poco visto. Además, a lo largo de las páginas, logra fomentar un dialogo constructivo, complementando ciertas lagunas en mi trabajo con sus propias investigaciones jurídicas en torno al campo de justicia transicional.

Una cuestión que une su investigación jurídica crítica y la mía es nuestra postura frente al dogma de que todas las víctimas de graves violaciones de derechos humanos desean que los perpetradores sean llevados ante la justicia y merezcan un castigo penal. Para decirlo en palabras de Pierre Hazan, la lucha contra la impunidad se ha convertido en «una moral absoluta, afirmando con convicción que solamente mediante la judicialización de los perpetradores de estos crímenes se detendrá su repetición» (2010, p. 49). Efectivamente, esta convicción es fundamental en la cultura legal dominante de justicia transicional.

Las narrativas mayas q'eqchi', discutidas en mi libro, demuestran que este dogma genera problemas dentro de las ontologías indígenas. Javier Dorado hace una lectura adicional a este credo, indicando que esto no es algo específico de ciertas visiones contra-hegemónicas indígenas, más bien que simplemente no existe «una psique unitaria» de víctimas. En lo que alcanzo a conocer, hay pocos juristas que cuestionen radicalmente este credo, reconociendo que no todas las víctimas quieren la persecución penal de los victimarios. Desde esta perspectiva crítica, mi colega da una lectura interesante al resultado del referéndum de 2016 sobre los Acuerdos de Paz entre el gobierno de Colombia y la guerrilla de las Fuerzas Armadas Revolucionarias de Colombia (FARC), conocido como «el plebiscito». Según Javier Dorado, entre las prioridades de las víctimas en los primeros momentos de 'transición', cuando la paz y la seguridad todavía no han sido alcanzadas, no aparece de forma especialmente relevante el castigo penal de los perpetradores. Por lo tanto, esta es una de las razones por las que el sí a los Acuerdos de Paz alcanzó cotas más altas, precisamente, en las zonas más golpeadas y con más víctimas por el conflicto.

En un segundo punto de su análisis jurídico crítico de este tema, Javier Dorado demuestra además que el campo de los derechos humanos y la justicia transicional no es un campo estático ni homogéneo. Nos explica que la postura maximalista inicial de la experta Diane Orentlicher, autora del Conjunto de Principios Actualizado para la Protección y la Promoción de los Derechos Humanos mediante la Lucha contra la Impunidad (Doc. ONU E/CN.4/2005/102/Add.1), se ha relativizado en el transcurso del tiempo, reconociendo que esta norma global de persecución penal debe ser matizada.

Sus reflexiones críticas al -casi-corazón original de la justicia transicional me hace recordar otros dos senderos que constituyen partes clave de mi tejido de 
pensamiento. Por un lado, me invita a reflexionar sobre mi recorrido académico «antes» de mi giro antropológico jurídico que predomina en mi trabajo actual. Como indiqué brevemente en la introducción de mi libro, mi investigación doctoral en derecho surgió desde una investigación empírica en el marco de mi tesis de maestría en antropología. Sin embargo, debo reconocer que las semillas de esta tesis de maestría y de mi trabajo de investigación posterior fueron sembradas por mis profesores de la carrera de criminología, que en Bélgica forma parte de la Facultad de Derecho. A finales de los ' 90 , un grupo de profesores jóvenes $-y$ alguno más senior- en la Universidad de Lovaina (Universiteit Leuven) junto con otros investigadores internacionales, sobre todo de Canadá, estaban en la primera línea del nacimiento de un paradigm shift en el derecho penal: la justicia restaurativa.

Efectivamente, hace más de veinte años aprendí de sus investigaciones que el sistema de justicia debería tomar las necesidades de las víctimas en serio, que la transformación de los perpetradores es clave y que el castigo penal no es la única respuesta a un delito criminal. Además, durante estos cuatro años fui formada en un pensamiento interdisciplinario y crítico, aprendiendo de mis profesores «not take for granted lo que sea dominante en el pensamiento académico». Nuestros profesores, como el finado Tony Peters, Lode Walgrave (emeritus ahora) y Stephan Parmentier nos enseñaron el valor de trabajar desde los márgenes, rompiendo dogmas académicos y la importancia de impulsar pensamientos y conocimientos innovadores basados en investigaciones empíricas ${ }^{4}$. Espero que con el proyecto RIVERS pueda caminar en este mismo sendero siguiendo sus pasos, aunque desde otros enfoques académicos.

Por otro lado, me hace revivir una experiencia profesional que tuve durante mis años en la Oficina del Alto Comisionado para los Derechos Humanos (OACNUDH) en Ecuador, donde estuve a cargo de las líneas de derechos colectivos y de justicia transicional, lo que está relacionado con mi perfil de criminóloga. A solicitud de abogados, víctimas y familiares de víctimas de violaciones de derechos humanos investigados por la Comisión de la Verdad, la Oficina co-organizó, en febrero 2013, con colegas del Programa Andino de Derechos Humanos de la Universidad Andina Simón Bolivar y la Fundación INREDH, un Encuentro Nacional. Su principal objetivo fue generar un espacio de encuentro de víctimas, familiares y organizaciones de apoyo, bajo la fórmula de actividades de formación, socialización de experiencias y de diálogo, tendente a fortalecer sus capacidades de organización de cara a proseguir su lucha por la justicia, la verdad y la reparación de las violaciones sufridas.

Este Encuentro Nacional de dos días fue el primero después de que la Comisión de la Verdad de Ecuador presentara en Quito su informe final en 2010. Este Informe detalló una serie de vulneraciones de derechos humanos perpetrados entre los años 1984-2008 y, de manera particular, durante el gobierno de León Febres Cordero (1984-1988) donde se dieron violaciones sistemáticas producto de su política de estado. Los resultados que arrojaron las investigaciones hechas por la Comisión de la Verdad fueron: 456 víctimas, 831 violaciones de derechos humanos, $65 \%$ en el período ' $84-' 88$, tortura $44 \%$, privación ilegal de la libertad $32 \%$, violencia sexual $10 \%$, ejecución extrajudicial $8 \%, 459$ personas responsables de las cuales $50 \%$ pertenece a la Policía Nacional y $28,3 \%$ a las Fuerzas Armadas ${ }^{5}$. El Informe terminó con 155

\footnotetext{
4 Véase: The International Journal of Restorative Justice. Disponible en https://www.elevenjournals.com/tijdschrift/IJRJ/2018/1/IJRJ 2589-08912018001001001

5 Más información: Comisión de la Verdad, 2010, Informe Final de la Comisión de la Verdad Ecuador. Sin Verdad no hay justicia, p.426. Disponible en:

https://issuu.com/triguero/docs/ecuador. sin verdad no hay justicia
} 
recomendaciones al Estado Ecuatoriano, entre ellas, en materia de satisfacción, restitución, indemnización y garantías de no repetición.

El Encuentro Nacional incluyó videoconferencias con la Presidenta de Madres de Plaza de Mayo, Línea Fundadora de Argentina, el director del Centro de Memoria Paz y Reconciliación de Colombia y con el equipo técnico del Relator Especial de Naciones Unidas sobre promoción de la verdad, de justicia, la reparación y garantías de no repetición. Además, cada día hubo talleres internos fomentando reflexiones sobre un enfoque integral de justicia transicional, sobre propuestas de fortalecimiento de organización, sobre necesidades y estrategias de seguimiento.

Efectivamente, en la línea de las reflexiones de Javier Dorado, estos días desvelaron que entre las víctimas y familiares de víctimas «sus deseos, intereses y necesidades pueden variar de unas a otras». Una sistematización de las expectativas de quienes fueron víctimas demostró múltiples necesidades en distintos ámbitos y niveles: «formar un solo grupo de víctimas y familiares de víctimas», «que se llega a la verdad de los casos y que se haga justicia», "saber qué pasó con mi hijo», "que las instituciones estatales nos den oídos», «justicia aquí y ahora cárcel para los torturadores que siguen campantes en el país», "coalición entre todas las organizaciones de derechos humanos» ${ }^{6}$.

Este Book Forum no es el espacio para profundizar más en el caso ecuatoriano de justicia transicional, sin embargo, este Encuentro demuestra otra vez más, junto con las reflexiones críticas de mi colega, el porqué de la importancia de la participación efectiva de las víctimas en el desarrollo de intervenciones de justicia transicional formales e informales, vía políticas públicas y/o programas de la comunidad internacional. Me pregunto, ¿por qué es el dogma del castigo penal en la justicia transicional tan persistente, mientras que el reconocimiento de la centralidad de las necesidades de las víctimas en las políticas de justicia transicional queda muchas veces en un nivel retórico? Para cerrar esta parte de mi camino al revés, planteo que por principio nunca he estado a favor de dogmas, sin embargo, si la justicia transicional debe tener dogmas, propongo un shift urgente del dogma del castigo penal hacia un dogma sobre la centralidad de las necesidades de los sobrevivientes en su diseño e implementación.

\section{De la diferencia cultural a la colonialidad jurídica y los conflictos ontológicos}

Para seguir tejiendo pensamientos necesito indicar que, en el campo de la justicia transicional, es muy reciente el reconocimiento de la gran necesidad de crear plataformas sostenibles de comunicación continua entre abogados, investigadores, practitioners y financiadores de varias regiones geopolíticas (Fletcher y Weinstein, 2018). Esta es una de las necesidades que surgió durante un taller internacional «North-South Dialogue: Briding the Gap in Transitional Justice» que se organizó en Berkeley Law (EEUU), en 2017, donde participaron 25 personas, tanto académicos como practicantes reconocidos, tanto del «Norte Global» como del «Sur Global«». Aparentemente, una de las discusiones centrales de este taller fue cómo la desigualdad de poder y las secuelas del colonialismo afectan al trabajo académico y de policy sobre justicia transicional (Fletcher y Weinstein, 2018, p. 195).

Este espacio de Book Forum genera justamente este canal de comunicación, poco común no solamente en el campo de la justicia transicional, sino también en el

\footnotetext{
${ }^{6}$ Memoria de trabajo Encuentro Nacional Fortalecimiento de Organizaciones de víctimas y familiares de víctimas de violaciones de derechos humanos, Ecuador, Quito, 27 y 28 de febrero 2013. Disponible en archivo personal de la autora.
} 
mundo jurídico en general. Por un lado, gracias a esta invitación tuve la gran oportunidad de conocer el trabajo académico innovador e inspirador del investigador indígena mexicano Pedro Garzón López con respecto al pluralismo jurídico, el derecho indígena y la colonialidad jurídica, el cual resuena mucho con las cuestiones que estamos planteando dentro el proyecto RIVERS. Por otro lado, su reseña de mi libro representa, aunque el mismo no lo reclama de forma tan explícita, una lectura crítica y muy apreciada desde ese Sur Global.

Pedro Garzón indica que este libro Nimla rahilal. Pueblos indígenas y justicia transicional: reflexiones antropológicas (Viaene, 2019) logró «poner los puntos sobre las "íes" al cuestionar la visión académica dominante de la justicia transicional desde las visiones y prácticas indígenas». A su vez, debo agradecerle que él mismo ponga las "íes" sobre este trabajo, aconsejándome no parar mi análisis teórico-práctico crítico en la cuestión de la diferencia cultural, sino ir más allá, reconociendo la necesidad de descolonizar la justicia transicional. Ciertamente, caminando al revés debo reconocer que este libro contiene varias lagunas por espacios inexplorados en su momento que hoy en día son imprescindibles en mi trabajo académico ${ }^{7}$. Estoy totalmente de acuerdo con su análisis-teórico crítico en el campo de derecho, los derechos humanos y la justicia transicional, en que es necesario «desvelar la colonialidad jurídica presente en la teoría y práctica del derecho occidental».

Como mencioné arriba, el nuevo sendero académico que estoy caminando con el equipo RIVERS tiene como objetivo no solamente crear un diálogo empírico con los avances teóricos en el campo de los derechos humanos y el pluralismo cultural, sino también con las teorías de descolonización de los derechos humanos. Aquí, el concepto teórico de "colonialidad jurídica» propuesto por Pedro Garzón (2019) brinda una herramienta analítica conceptual clave para analizar más críticamente la continuidad del modelo jurídico colonial en las teóricas y prácticas, tanto de los derechos humanos como de la justicia transicional. Efectivamente, los análisis desde «la diferencia cultural» omiten reconocer que las diferencias entre pueblos indígenas y el Estado es también colonial en el sentido de que los sistemas normativos indígenas «conviven en un contexto de subordinación colonial sin desenmascarar la colonialidad del poder que subyace en la trilogía moderna: Estado/soberanía/derecho» (Garzón, 2019, p. 216).

Agradezco su invitación a añadir la dimensión del poder colonial en un análisis crítico del campo de la justicia transicional porque, ciertamente, las políticas públicas de justicia transicional en Guatemala, como, por ejemplo, el Programa Nacional de Resarcimiento, solamente han reforzado las estructuras de dominación y discriminación. De hecho, de la misma manera que Pedro Garzón cuestiona la «interculturalidad» como mecanismo de legitimación de las relaciones de dominación, también la investigadora indígena maya Aura Cumes (2019) critica «la famosa "interculturalidad", entendido como neo-folklor, un mecanismo usado cómodamente desde el poder para pacificarnos a los Pueblos Indígenas y Afrodescendientes, generando la percepción de que no está "incluyendo" en un mundo hecho a su medida».

Cuando se habla de que la justicia transicional debe «tomar al otro en serio», significa efectivamente «incluir las concepciones indígenas de perjuicios a las montañas, cerros y ríos en la arena jurídica» (Izquierdo y Viaene, 2018), y no descartarlos como "fenómenos infra-jurídicos» (Garzón, 2019, p. 223). Aquí es importante destacar la labor de vanguardia jurisprudencial que la magistrada indígena Belkis Izquierdo, de la Jurisdicción Especial para la Paz (JEP) en Colombia, está

\footnotetext{
${ }^{7}$ Ver por ejemplo: B. Izquierdo y L. Viaene (2018) y L., Viaene, y G., Fernández-Maldonado (2018).
} 
impulsando con su auto innovador de noviembre del año pasado que reconoce al "Katsa Su», gran territorio Awá y a los 32 Cabildos indígenas Awá, asociados y representados en la Unidad Indígena del Pueblo Awá - Asociación de Autoridades Tradicionales Indígenas Awá -, como víctimas en calidad de sujetos colectivos de derechos ${ }^{8}$.

Como parte de este diálogo también quisiera plantear que es necesario añadir los debates en torno a los "conflictos ontológicos" ${ }^{9}$ cuando se discuten visiones y practicas indígenas con respecto a la justicia, la reparación, la memoria y la reconciliación. Como he escrito con la magistrada Belkis Izquierdo en otro lugar, «la visión hegemónica de los derechos humanos aún no se ha enfrentado a las visiones indígenas que cuestionan las divisiones de la ontología moderna dominante entre cultura/naturaleza, mente/cuerpo, humanos/no humanos, creencia/realidad» (Izquierdo y Viaene, 2018).

Como última reflexión en clave de caminar al revés, leyendo todas reflexiones de mis interlocutores, me he acordado que una de las modalidades del dialogo en la cultura maya es el consejo que «marca el inicio de una nueva relación y es, por tanto, un acto fundador» (Ochoa García, 2014, p. 9). Por lo tanto, estoy muy agradecida por su generosidad de haber tomado el tiempo de pensar y dialogar con este libro, además de darme consejos, algo que en sí ya genera una labor académica cocreadora de un pensamiento y una práctica crítica de los derechos humanos.

Y como dijo Javier Dorado Porras a final de su reseña: «hay un importante trabajo por hacer»... Sí, timil timil, poco a poco, como dicen los q'eqchi'. Ojalá podamos seguir tejiendo pensamientos y, de vez en cuando, caminar conjuntamente al revés.

\section{Bibliografía}

Blaser, M. (2019). Reflexiones sobre la ontología política de los conflictos medioambientales. América Crítica, Vol. 3, N. 2, pp. 61-79.

Blaser, M. (2013). Ontological Conflicts and the Stories of Peoples in Spite of Europe. Toward a Conversation on Political Ontology. Current Anthropology, 54(5), pp. 547-568

Cumes, A. (2019). "Lo indígena" como circo en el regreso de la interculturalidad, Tujaal.org. Recuperado de http://tujaal.org/lo-indigena-como-circo-en-el-regresode-la-interculturalidad/

De la Cadena, M. (2015). Earth Beings. Ecologies of Practice across Andean Worlds. Durham: Duke University Press.

Fletcher, L. y Weinstein, H. (2018). How power dynamics influence the "North-South" Gap in Transitional Justice. Berkeley Journal of International Law, 36 (2), pp. 190217.

Garzón, P. (2019). Pluralismo jurídico, derecho indígena y colonialidad jurídica: repensando el derecho desde la colonialidad del poder. Ius Inkarri. Revista de la Facultad de Derecho y Ciencia Política, 8, pp. 215-226.

Hazan, P. (2010). Judging war, judging history, Behind Truth and Reconciliation. Stanford, Estados Unidos: Stanford University Press.

Ingold, T. (2018). Anthropology: Why it matters, Medford. Estados Unidos: Polite

\footnotetext{
8 Jurisdicción Especial para la Paz (JEP), Sala de Reconocimiento de Verdad, de Responsabilidad y Determinación de los Hechos y Conductas, Caso No. 2 de 2018, "Acreditar como víctimas en calidad de sujetos colectivos de derechos al "Katsa Su», gran territorio Awá y a los 32 Cabildos indígenas Awá, asociados y representados en la Unidad Indígena del Pueblo Awá - Asociación de Autoridades Tradicionales Indígenas Awá - UNIPA en el marco del Caso 02, 12 de noviembre 2019.

${ }^{9}$ Véase entre otros: M., Blaser (2019 y 2013) y De la Cadena (2015).
} 
Press.

Izquierdo, B y Viaene, L. (2018). Descolonizar justicia transicional desde los territorios indígenas. Peace in Progress, 34, Instituto Catalán Internacional para la Paz (ICIP).

Lykes, M. y van der Merwe, H. (2019). Critical reflexivity and transitional justice praxis: solidarity, accompaniment and intermediarity. International Journal of Transitional Justice, 13, pp. 411-416.

Ochoa, C. F. (2014). Dialogo: señal de nuestra existencia. Retal Qatzij. Concepción, uso y manejo del diálogo por las autoridades indígenas. Guatemala: Asociación de Investigación y Estudios Sociales (ASIES).

Viaene, L. y Fernández-Maldonado, G. (2018). Legislating coordination and cooperation mechanisms between indigenous and ordinary jurisdictions: reflections on progress and setbacks in Ecuador. En Corradi, G., De Feyter, K., Desmet, E. y Vanhees, K. (eds.), Critical indigenous rights studies. New directions in indigenous rights research (pp. 201-226., Londres, Reino Unido: Routledge.

Zinsstag, E., Aertsen, I., Walgrave L. e.a. (2018). The International Journal of Restorative Justice: new horizons for independent research and development. The International Journal of Restorative Justice, pp. 3-8. 